\title{
Effect of Muscle Vibration on Postural Balance of Parkinson's Diseases Patients in Bipedal Quiet Standing
}

\author{
Jintae Han, PT, $\mathrm{PhD}^{1)}$, Jaemin Jung, $\left.\mathrm{PhD}^{2}\right)^{*}$, Junghoon Lee, PT, PhD ${ }^{3)}$, \\ Eunjung Kim, PT, PhD ${ }^{4)}$, Myunghee Lee, PT, PhD ${ }^{1)}$, Keunhee Lee, PT, PhD ${ }^{5)}$ \\ 1) Department of Physical Therapy, College of Science, Kyungsung University, Republic of Korea \\ 2) Department of Physical Therapy, Gimhae University: 77-9 San, Sambang-dong, Gimhae city, \\ Kyungsannam-do, Republic of Korea \\ 3) Department of Physical Therapy, Inje University Pusan Paik Hospital, Republic of Korea \\ 4) Department of Physical Therapy, Masan University, Republic of Korea \\ 5) Lee Keun Hee's Pediatric Development Research Institute, Republic of Korea
}

\begin{abstract}
Purpose] The purpose of this study was to investigate the effect of muscle vibration applied to the lower extremities on static postural balance of patients with Parkinson's disease (PD). [Subjects] Seven subjects with Parkinson's disease participated in this study. [Methods] The oscillators of vibration were attached to the muscle bellies of the tibialis anterior, gastrocnemius, biceps femoris, and rectus femoris on both sides of the lower extremities with adhesive tape. A vibration frequency of $60 \mathrm{~Hz}$ was used to induce static postural reactions. Subjects' center of pressure (COP) sway and peak ground reaction force (GRF) were measured with their eyes open with and without vibration. COP sway and peak GRF (Fx, Fy, Fz) were measured using a force plate (AMTI, Newton, USA), which provides $\mathrm{x}, \mathrm{y}$ and $\mathrm{z}$ coordinates of body movement. [Results] The area of COP sway with vibration was significantly smaller than that with no vibration, but the length of COP sway showed no difference between two conditions. Peak medial-lateral maximum force (Fy) with vibration was significantly higher than that with no vibration, but peak anterior-posterior force $(\mathrm{Fx})$ and peak vertical force $(\mathrm{Fz})$ showed no differences. [Conclusion] These results suggest that vibration applied to the lower extremities can help PD patients control postural balance during quiet standing. Key words: Vibration, Postural balance, Parkinson's disease
\end{abstract}

(This article was submitted Apr. 2, 2013, and was accepted Jun. 20, 2013)

\section{INTRODUCTION}

Quiet standing postural balance is an indispensable factor for performing routine activities of daily living ${ }^{1)}$. The maintenance of a quiet stance is a complicated task that requires the integration of vestibular, visual and somatosensory inputs from the whole body, for the assessment of the motion and position of the body in space, and the ability to generate forces to adjust body position ${ }^{2}$. Disorders in these postural control systems often result in falls, and falls are a potential risk, limiting activities of daily living of patients with Parkinson's disease ${ }^{3)}$. Patients with Parkinson's disease have problems maintaining balance and coordinating goal directed movements ${ }^{4)}$. In particular, the contributions of proprioceptive feedback information to static position and movement perception processing are decreased in patients with Parkinson's disease ${ }^{5}$. Therefore, Parkinsonian

*Corresponding author. Jaemin Jung (e-mail: 6240394@ hanmail.net)

(C)2013 The Society of Physical Therapy Science

This is an open-access article distributed under the terms of the Creative Commons Attribution Non-Commercial No Derivatives (by-ncnd) License $<$ http://creativecommons.org/licenses/by-nc-nd/3.0/>. patients have smaller than normal limits of stability when asked to perform quiet standing ${ }^{6)}$. Since the center of pressure (COP) and ground reaction force (GRF) are very important variables for the maintenance of postural control, we need to evaluate the COP sway and GRF as a clinical method of functional assessment ${ }^{7,8}$ ).

Also, because movement disability is the main symptom of patients with Parkinson's disease, exercise training is very important, and a recommended intervention in terms of exercise that helps functional rehabilitation and decreases the side-effects of medications for Parkinson's disease $\left.^{9,}, 10\right)$. However, it is difficult to develop a specific therapeutic exercise for these symptoms which include hypokinesia, tremor, and muscular rigidity ${ }^{11)}$.

Recently, various devices and exercise interventions have been developed to replace the loss of self-motion information due to disease, injury or aging. Among these, the application of vibration has been widely used to improve the function of proprioception ${ }^{12}$. Vibration improves stance control and muscle performance of sedentary elderly wom$\mathrm{en}^{13)}$. However, Ross et al. ${ }^{14)}$ reported that vibration applied to young healthy individuals did not affect their static balance. Some studies have reported that vibration improved the postural balance of patients with neurological injury, 
whereas the others have reported no difference. Therefore, the effects of vibration remain controversial.

The purpose of this study was to investigate if the application of vibration to the lower extremities affects the quiet standing postural balance of patients with Parkinson's disease

\section{SUBJECTS AND METHODS}

Seven patients with Parkinson's disease participated in this study. The subjects had an average age of $61.82 \pm$ 5.57 , an average height of $155.36 \pm 3.71 \mathrm{~cm}$, and an average weight of $60.15 \pm 4.38 \mathrm{~kg}$. Approval for the study was received from the institutional review board of National Evidence-based Healthcare Collaborating Agency (PIRB11015-1), and written informed consent was obtained from each patient before the start of the study.

Eight vibrators $(10 \mathrm{~g}$, diameter of $1 \mathrm{~cm})$ were made especially for this study. They were attached to the muscle bellies of the tibialis anterior, gastrocnemius, biceps femoris, and rectus femoris on both sides of the lower extremities of the subjects. The subjects wore short pants to minimize external stimuli, and were barefoot. To identify the effects of vibration stimuli on static postural balance, subjects asked to stand on a force platform and measurement were made with and without vibration applied to both of the lower extremities. The force platform (AMTI, Newton, MA, USA) measured the center of pressure (COP) sway and ground reaction forces (GRF) during quiet standing. The amplified force platform signals were sampled on-line at a rate of $1,000 \mathrm{~Hz}$ for 1 second and COP data (path length, path area) and GRF (Fx, Fy, Fz) were calculated using BioAnalysis (AMTI, Watertown, MA, USA). The independent t-test was used to identify the significance of differences in the length and area of COP sway and GRF (medial/lateral, anterior/ posterior, vertical force) between with and without vibration stimuli. Significance was accepted for values of $p<0.05$.

\section{RESULTS}

The length of COP sway of the Parkinson's disease pa-

Table 1. Comparison of center of pressure sway between with and without vibration

\begin{tabular}{lcc}
\hline Variable & Without vibration & With vibration \\
\hline Path length $(\mathrm{mm})$ & $1,419.36(276.04)$ & $1,425.31(262.08)$ \\
Path area $\left(\mathrm{m}^{2}\right)$ & $266.66(139.71)$ & $122.19(60.14)^{*}$ \\
\hline
\end{tabular}

*significant difference between with and without vibration $(\mathrm{p}<0.05)$ tients was not significantly different between with and without vibration ( $p>0.05)$, but the area of COP sway with vibration was significantly smaller than that without vibration $(p<0.05)$ (Table 1). For GRF, the medial-lateral maximum force (Fy) with vibration was significantly higher than that with no vibration $(\mathrm{p}<0.05)$, but the antero-posterior force (Fx) and vertical force $(\mathrm{Fz})$ showed no significant differences (Table 2).

\section{DISCUSSION}

Parkinson's disease is characterized by tremor, postural reflex disorder, and rigidity, which increase the risk of falls ${ }^{15}$. The symptoms of Parkinson's disease have been implicated in several aspects of the postural control and locomotor systems including the integration of sensory information relevant for balance ${ }^{16}$.

This study demonstrated the effects of vibration on the postural balance of Parkinson's disease patients in quiet standing. Patients with Parkinson's disease often have larger than normal center of mass displacements in response to external perturbations ${ }^{17}$ ), and they have problems integrating proprioceptive information for posture-movement coordination ${ }^{4}$. Vibratory stimulation increases the afferent signals generated by the muscle spindles creating a proprioceptive illusion ${ }^{18)}$. Vibration can also evoke postural adaptation enhancing postural performance and reducing the likelihood of imbalance ${ }^{19)}$.

In our study of Parkinson's disease patients, the area of COP sway with vibration was significantly smaller and the medial-lateral force (Fy) with vibration was significantly higher than that of the no vibration condition. These results are similar to those of previous studies which have reported that vibration can affect postural reactions and creat postural kinesthetic illusions in standing subjects ${ }^{20,21)}$. We believe that the decrease of the area of COP sway and the increase of medial-lateral force induced by vibration indicates a more rapid reaction to posture perturbation.

In conclusion, our results suggest that the application of vibration stimuli to the lower extremities can help Parkinson's disease patients to control postural balance during quiet standing.

\section{ACKNOWLEDGEMENT}

This research was supported by the Basic Science Research Program through the National Research Foundation of Korea (NRF) funded by the Ministry of Education, Science and Technology (2011-0008849).

Table 2. Comparison of ground reaction forces between with and without vibration

\begin{tabular}{lcc}
\hline Variable & Without vibration & With vibration \\
\hline Anterior-posterior (\%BM) & $0.00290(0.00207)$ & $0.00391(0.00215)$ \\
Medial-lateral (\%BM) & $0.00338(0.00257)$ & $0.00604(0.00234)^{*}$ \\
Vertical (\%BM) & $1.03674(0.07680)$ & $1.03694(0.07649)$ \\
\hline
\end{tabular}

*significant difference between with and without vibration $(\mathrm{p}<0.05)$ 


\section{REFERENCES}

1) Ferdjallah M, Harris GF, Smith P, et al.: Analysis of postural control synergies during quiet standing in healthy children and children with cerebra palsy. Clin Biomech (Bristol, Avon), 2002, 17: 203-210. [Medline] [CrossRef]

2) Massion J: Postural control system. Curr Opin Neurobiol, 1994, 4: 877887. [Medline] [CrossRef]

3) Wood BH, Bilclough JA, Bowron A, et al.: Incidence and prediction of falls in Parkinson's disease: a prospective multidisciplinary study. J Neurol Neurosurg Psychiatry, 2002, 72: 721-725. [Medline] [CrossRef]

4) Tagliabue M, Ferrigno G, Horak F: Effects of Parkinson's disease on proprioceptive control of posture and reaching while standing. Neuroscience, 2009, 158: 1206-1214. [Medline] [CrossRef]

5) Keijsers NL, Admiraal MA, Cools AR, et al.: Differential progression of propioceptive and visual information processing deficits in Parkinson's disease. Eur J Neurosci, 2005, 21: 239-248. [Medline] [CrossRef]

6) Mancini M, Rocchi L, Horak FB, et al.: Effects of Parkinson's disease and levodopa on functional limits of stability. Clin Biomech (Bristol, Avon), 2008, 23: 450-458. [Medline] [CrossRef]

7) Benda BJ, Riley PO, Krebs DE: Biomechanical relationship between center of gravity and center of pressure during standing. Trans Rehabil Eng, 1994, 2: 3-10. [CrossRef]

8) Giakas G, Baltzopoulos V, Dangerfield PH, et al.: Comparison of gait patterns between healthy and scoliotic patients using time and frequency domain analysis of ground reaction forces. Spine, 1996, 21: 2235-2242. [Medline] [CrossRef]

9) Ashburn A, Fazakarley L, Ballinger C, et al.: A randomized controlled trial of a home based exercise programme to reduce the risk of falling among people with Parkinson's disease. Am J Phys Med Rehabil, 2007, 78 678-684.

10) Kluding P, McGinnis PQ: Multidimensional exercise for people with Parkinson's disease: a case report. Physiother Theory Pract, 2006, 22: 153-
162. [Medline] [CrossRef]

11) Reuter I, Engelhardt M: Exercise training and Parkinson's disease: placebo or essential treatment? Phys Sportsmed, 2002, 30: 43-50. [Medline] [CrossRef]

12) Courtine G, Marco De Nunzio A, Schmid M, et al.: Stance -and locomotion dependent processing of vibration-induced proprioceptive inflow from multiple muscles in humans. J Neurophysiol, 2007, 97: 772-779. [Medline] [CrossRef]

13) Filippi GM, Brunetti O, Botti FM, et al.: Improvement of stance control and muscle performance induced by focal muscle vibration in young-elderly women: a randomized controlled trial. Arch Phys Med Rehabil, 2009, 90: 2019-2025. [Medline] [CrossRef]

14) Pollock RD, Sally P, Finbarr CM, et al.: The effects of whole body vibration on balance, joint position sense and cutaneous sensation. Eur J Appl Physiol, 2011, 111: 3069-3077. [Medline] [CrossRef]

15) Gray P, Hildebrand K: Fall risk factors in Parkinson's disease. J Neurosci Nurs, 2000, 32: 222-228. [Medline] [CrossRef]

16) Peterka RJ: Sensorimotor integration in human postural control. J Neurophysiol, 2002, 88: 1097-1118. [Medline]

17) Horak FB, Dimitrova D, Nutt JG: Direction-specific postural instability in subjects with Parkinson's disease. Exp Neurol, 2005, 193: 504-521. [Medline] [CrossRef]

18) Gomez S, Patel M, Berg S, et al.: Effects of proprioceptive vibration on body movement at 24 and $36 \mathrm{~h}$ of sleep deprivation. Clin Neurophysiol, 2008, 119: 617-625. [Medline] [CrossRef]

19) Pavol MJ, Pai YC: Feedforward adaptations are used to compensate for a potential loss of balance. Exp Brain Res, 2002, 145: 528-538. [Medline] [CrossRef]

20) Valkovic P, Krafczyk S, Bötzel K: Postural reactions to soleus muscle vibration in Parkinson's disease: scaling deteriorates as disease progresses. Neurosci Lett, 2006, 401: 92-96. [Medline] [CrossRef]

21) Lackner JR, Levne MS: Changes in apparent body orientation and sensory localization induced by vibration of postural muscles: vibratory myesthetic illusion. Aviat Space Environ Med, 1979, 50: 460-465. 